\title{
Atributos físicos do solo relacionados ao armazenamento de água em um Argissolo Vermelho sob diferentes sistemas de preparo ${ }^{1}$
}

\author{
Soil physics properties related to water storage and tillage systems in a Loamy Acrisol \\ Mellissa Ananias Soler da Silva ${ }^{2}$ Álvaro Luiz Mafra ${ }^{3}$ Jackson Adriano Albuquerque $^{3}$ \\ Cimélio Bayer ${ }^{4}$ João Mielniczuk ${ }^{4}$
}

\section{RESUMO}

Os sistemas de preparo afetam a estrutura do solo e podem influenciar o armazenamento de água disponível para as plantas. $O$ objetivo deste estudo foi avaliar o efeito de longo prazo (17 anos) dos sistemas de preparo convencional (PC), preparo reduzido $(P R)$ e semeadura direta $(S D)$ sobre os atributos físicos relacionados ao armazenamento e disponibilidade de água de um Argissolo Vermelho com textura média, em Eldorado do Sul, RS. Amostras de solo (0-2,5, 2,5-7,5, 7,5-12,5, 12,5$17,5 \mathrm{~cm})$ foram coletadas numa seqüencia ervilhaca/milho. Adicionalmente, amostrou-se uma área sob campo nativo (CN), adjacente à área experimental, como referência à condição natural do solo. $O$ solo em SD apresentou maiores teores de carbono orgânico (CO) na camada superficial e maiores valores de resistência ao penetrômetro em profundidade, em relação ao solo em preparo convencional. Os sistemas de preparo não se diferenciaram quanto ao seu efeito na macro e microporosidade do solo, contudo o revolvimento no PC aumentou a condutividade hidráulica saturada em profundidade. Não se verificou nenhuma restrição física ao desenvolvimento radicular sob os diferentes sistemas de preparo, o que foi comprovado pelos valores de densidade $\left(1,35\right.$ a $\left.1,65 \quad \mathrm{Mg} \mathrm{m}^{-3}\right)$, macroporosidade $\left(0,09\right.$ a $\left.0,20 \mathrm{~m}^{3} \mathrm{~m}^{-3}\right)$ e resistência ao penetrômetro $(0,25$ a 0,75 MPa). Do ponto de vista hídrico, as curvas de retenção e o volume de água disponível $(\mathrm{AD}=10 \mathrm{kPa}$ (capacidade de campo) - $1.500 \mathrm{kPa}$ (ponto de murcha permanente)), não foram influenciados pelos sistemas de preparo, sendo o baixo volume de água disponível (0,05 a 0,09 $\mathrm{m}^{3} \mathrm{~m}^{-3}$ ) relacionado à textura desse solo. Nesse caso, o aumento da taxa de infiltração e a diminuição da evaporação da água decorrente da manutenção dos resíduos vegetais sobre o solo nos sistemas de preparo reduzido e semeadura direta, podem contribuir para uma maior disponibilidade hídrica na fase inicial do estabelecimento das culturas nesses sistemas conservacionistas de manejo em comparação ao preparo convencional.

Palavras-chave: curva de retenção de água, condutividade hidráulica saturada, densidade do solo, porosidade, resistência ao penetrômetro.

\section{ABSTRACT}

The tillage systems affect the soil structure, and influence the storage of water available to plants. The objective of the present study was to evaluate the effects of long-term (17 years) of conventional tillage $(P C)$, reduced tillage $(P R)$ and no tillage (SD) on soil physical properties related to water storage in a Loamy Acrisol, in Eldorado do Sul, Rio Grande do Sul State. Soil samples (0-2.5, 2.5-7.5, 7.5-12.5, $12.5-17.5 \mathrm{~cm}$ ) were collected in a sequence of vetch/corn and in an adjacent native grass field. The soil in SD presented high organic carbon (CO) for the superficial layer and large soil resistance values for depth compared to the conventional tillage. There were no differences among tillage systems of macro and microporosity of the soil, but for PC the saturated hydraulic conductivity increased in depth. No physical restriction to the plant root penetration in the soil under the different tillage systems was verified, which agrees with observation of non-critical observed values of bulk density (1.35 - $\left.1.65 \mathrm{Mg} \mathrm{m}^{-3}\right)$, macroporosity $\left(0.09-0.20 \mathrm{~m}^{3} \mathrm{~m}^{-3}\right)$ and soil resistance $(0.25-0.75 \mathrm{MPa})$. The water retention curves

${ }^{1}$ Parte da Dissertação de Mestrado do primeiro autor, apresentada à Universidade do Estado de Santa Catarina, Centro de Ciências Agroveterinárias (UDESC/CAV).

${ }^{2}$ Engenheiro Agrônomo, Doutorando em Agronomia: Solo e Água, Universidade Federal de Goiás, Escola de Agronomia (UFG/EA). Secretaria de pós-graduação, Rodovia Goiânia, Nova Veneza, km zero, CP 131, 74001-970, Goiânia, GO, Brasil. Email: melsoler@hotmail.com.

${ }^{3}$ Engenheiro Agrônomo, Doutor Professor do Departamento de Solos, UDESC/CAV, Brasil.

${ }^{4}$ Engenheiro Agrônomo, Doutor Professor do Departamento de Solos, Faculdade de Agronomia, Universidade do Rio Grande do Sul (UFRGS), Brasil. 
and the available water $(A D=10 \mathrm{kPa}$ (field capacity) $1.500 \mathrm{kPa}$ (point of permanent wither)) were not influenced by tillage systems, being the low volume of available water $\left(0.05-0.09 \mathrm{~m}^{3} \mathrm{~m}^{-3}\right)$ related to the texture of this soil. In this case, the increase of the infiltration rate and decrease of water evaporation due to the maintenance of the plant residues on soil surface for reduced tillage and no tillage may contribute to increase availability of water in the initial phase of crop establishment in these systems.

Keywords: soil water retention curve, saturated hydraulic conductivity, bulk density, porosity, penetrometer resistance.

\section{INTRODUÇÃO}

A mobilização mecânica e o tráfego de máquinas e implementos agrícolas interferem na estrutura e no grau de cobertura do solo, o que pode ocasionar alterações em seus atributos físicos e hídricos (UNGER \& CASSEL, 1991). Entre os aspectos negativos do preparo intensivo, pode-se destacar a redução da estabilidade de agregados, formação de camadas compactadas subsuperficiais, aumento da taxa de decomposição de matéria orgânica e exposição do solo à chuva, intensificando a erosão hídrica (ALEGRE et al., 1991).

As modificações provocadas pelo revolvimento na estrutura, distribuição do tamanho dos poros e teor de carbono orgânico, alteram as forças de retenção de água no solo e sua disponibilidade, os quais são fatores determinantes para o desenvolvimento de plantas em sistemas não irrigados. O preparo modifica também a rugosidade superficial, com a incorporação de resíduos vegetais, ocasionando diminuição da infiltração e aumento da evaporação de água. Além do manejo, a granulometria e constituição do solo influenciam a retenção de água, pois as forças de adsorção dependem, basicamente, da espessura do filme de água que recobre as partículas, a qual varia de acordo com sua superfície específica. Assim, a retenção de água é maior em solos argilosos e com alto teor de matéria orgânica.

Nesse sentido, a utilização de sistemas conservacionistas de preparo pode afetar o armazenamento de água em relação a sistemas de preparo convencional, o que tem sido reportado por alguns pesquisadores (SALTON \& MIELNICZUK, 1995; ROJAS \& VAN LIER, 1999; COSTA et al., 2003). Os sistemas de semeadura direta e preparo reduzido, os quais têm como premissa o não revolvimento ou a mínima mobilização do solo, bem como a manutenção dos resíduos culturais na superfície ou sua incorporação apenas parcial, podem contribuir para uma melhor condição físico-hídrica do solo, pela não formação de crostas superficiais, aumento da estabilidade de agregados devido ao acúmulo de matéria orgânica, estabelecimento de porosidade contínua (bioporos) pela atividade biológica da fauna edáfica e de raízes e o equilíbrio entre os valores de macro e microporosidade, que por sua vez podem contribuir para um maior volume de água disponível (SALTON \& MIELNICZUK, 1995).

O objetivo do estudo foi determinar os efeitos de sistemas de preparo do solo de longa duração (17 anos), sobre os atributos físicos relacionados ao armazenamento de água disponível de um Argissolo Vermelho de textura média.

\section{MATERIAL E MÉTODOS}

O estudo foi conduzido em experimento instalado em 1985, em Eldorado do Sul, RS, coordenadas 3005'52” Sul e 51³8'08”' Oeste. O solo é classificado como Argissolo Vermelho distrófico, relevo suave ondulado e altitude de $46 \mathrm{~m}$, com características físicas degradadas pelo cultivo convencional intenso desde 1970. O clima local é do tipo mesotérmico úmido com verão quente, Cfa segundo a classificação de Köppen, com temperatura média anual de $19^{\circ} \mathrm{C}$ e precipitação média anual de $1.440 \mathrm{~mm}$. O experimento consta de três sistemas de preparo e três sistemas de cultura, distribuídos segundo delineamento em blocos casualizados com parcelas subdivididas e duas doses de $\mathrm{N}$ em faixas nos blocos, em três repetições. Neste estudo, amostrou-se o solo no ciclo ervilhaca (Vicia sativa) / milho (Zea mays), com N mineral (180 kg ha-1), nos sistemas de preparo convencional (PC), preparo reduzido (PR) e semeadura direta (SD), na primavera-verão, anterior à cultura do milho. O PC consistiu em uma aração com arado de discos, seguida por duas gradagens, o PR foi realizado com escarificador a profundidade de $15-20 \mathrm{~cm}$, e a SD consistiu na manutenção dos resíduos vegetais na superfície do solo nas entrelinhas da cultura do milho com a semeadura sendo realizada com semeadora-adubadora com discos de corte para cortar a resteva e abertura do sulco para semeadura. Adicionalmente, amostrou-se uma área sob campo nativo (CN), adjacente ao experimento, como referência da condição natural do solo. Maiores detalhes da condução da área experimental, adubação e manejo das culturas são apresentados em BAYER et al. (2000).

A amostragem foi efetuada em Setembro, imediatamente antes dos preparos de solo, nas profundidades de $0-2,5 \mathrm{~cm}, 2,5-7,5 \mathrm{~cm}, 7,5-12,5 \mathrm{~cm}$ e 12,5$17,5 \mathrm{~cm}$, representando a camada superficial mobilizada pelo preparo e que seria mais representativa do ambiente radicular das culturas anuais. Foram determinados os teores de carbono orgânico (CO), granulometria, grau de floculação de argila, densidade do solo, macro, micro e porosidade total, condutividade hidráulica saturada e 
retenção de água no solo. Determinou-se o teor de CO pelo método da combustão úmida em amostras secas em estufa a $50{ }^{\circ} \mathrm{C}$, moídas e peneiradas a $0,105 \mathrm{~mm}$ (TEDESCO et al., 1995). A análise granulométrica foi realizada pelo método do densímetro, com estimativa da argila dispersa em suspensão com água destilada, e da argila total usando-se hidróxido de sódio como dispersante. O grau de floculação foi calculado com base nas quantidades de argila total e argila dispersa em água (EMBRAPA, 1997). A densidade do solo foi determinada pelo método do anel volumétrico, e a densidade de partículas pelo método do balão volumétrico. A microporosidade foi determinada em mesa de tensão de areia, com sucção de $60 \mathrm{~cm}$ e posterior secagem em estufa a $105^{\circ} \mathrm{C}$, com cálculo da porosidade total pela relação entre densidade do solo e de partículas, e da macroporosidade por diferença entre estas. A condutividade hidráulica saturada foi estimada pelo método da coluna constante de água, descrito em EMBRAPA (1997), com três determinações para cada amostra.

A resistência do solo foi determinada in situ, utilizando-se um penetrômetro de bolso com haste cilíndrica e escala de 0 a 5,0 $\mathrm{kg} \mathrm{cm}^{-2}$. Realizaram-se seis determinações (subamostras) em cada profundidade, tomadas horizontalmente na parede da trincheira aberta para coleta das amostras de solo. Os valores obtidos em $\mathrm{kg} \mathrm{cm}^{-2}$ foram convertidos em MPa através da multiplicação pelo fator 0,31 (ARSHAD et al., 1996). Coletou-se uma amostra de solo no local para avaliação da umidade no momento da penetrometria.

A curva de retenção de água foi determinada obtendo-se a umidade volumétrica em mesa de tensão de areia para o potencial matricial de -6 kPa e câmara de Richards, com placas porosas, para os potenciais de 10, -30, -100, -300, -500, -1.000, e -1.500 kPa. Para a obtenção dos pontos da curva, ajustou-se o modelo de VAN GENUCHTEN (1980) aos valores de potencial e umidade, com o uso do programa Soil Water Retention Curve - SWRC (DOURADO NETO et al., 2000). O volume de água disponível para as plantas na camada de 0 a $17,5 \mathrm{~cm}$ de profundidade foi estimado pela diferença entre a umidade volumétrica no potencial de $10 \mathrm{kPa}$, referido como capacidade de campo para solos de textura franco-arenosa, e $-1.500 \mathrm{kPa}$, considerado como ponto de murcha permanente (CARLESSO, 1995).

Os resultados foram submetidos à análise de normalidade pelo teste de Shapiro-Wilk. A variância foi feita pelo teste F e comparação de médias por Duncan em nível de 5\% de probabilidade de erro, com análise das interações por DMS. Utilizou-se teste de correlação de Pearson para verificar relações entre os diferentes atributos avaliados.

\section{RESULTADOS E DISCUSSÃO}

Teores de carbono orgânico e atributos físicos e hídricos do solo

Os teores de carbono orgânico no solo, nas profundidades estudadas, variaram entre $8,7 \mathrm{~g} \mathrm{~kg}^{-1}$ $(12,5-17,5 \mathrm{~cm})$ e $19,5 \mathrm{~g} \mathrm{~kg}^{-1}(0-2,5 \mathrm{~cm})$ (Tabela 1$)$, valores característicos de solos de textura franco-argiloarenosa, nos quais a fração mineral confere baixa proteção física da matéria orgânica à decomposição microbiana. A elevada temperatura média anual $\left(19^{\circ} \mathrm{C}\right)$ também contribui para elevadas taxas de oxidação biológica do CO do solo (BAYER et al., 2000). Os sistemas conservacionistas de preparo afetaram o teor de $\mathrm{CO}$, principalmente na camada superficial de $0-2,5 \mathrm{~cm}$, onde os resíduos culturais se concentram. Após 17 anos de implantação, a SD recuperou os teores de CO nessa camada (19,5 $\left.\mathrm{g} \mathrm{kg}^{-1}\right)$, a valores semelhantes ao do solo em CN (18,9 $\left.\mathrm{g} \mathrm{kg}^{-1}\right)$, e superior ao PC (13,1 $\mathrm{g} \mathrm{kg}^{-}$ $\left.{ }^{1}\right)$. Os teores de CO decresceram em profundidade em todos os sistemas de preparo, com exceção do PC, no qual a distribuição do CO foi mais uniforme em função da mobilização do solo anualmente, pela lavração e gradagens, que incorporam os resíduos culturais na camada movimentada.

O revolvimento do solo aumenta as taxas de perda de matéria orgânica (BAYER et al., 2000), o que se deve ao fracionamento e incorporação de resíduos vegetais, maior disponibilidade de oxigênio, maiores temperaturas e menor proteção física intra-agregados, reduzindo gradativamente os estoques de carbono orgânico. Por sua vez, a agregação e as alterações no microclima em solos sob semeadura direta contribuem para o acúmulo de matéria orgânica em solos não revolvidos, como tem sido verificado por diversos autores (BAYER et al., 2000; CASTRO FILHO et al., 2002).

Os teores de argila foram, em média, $194 \mathrm{~g} \mathrm{~kg}^{-1}$ na camada de $0-2,5 \mathrm{~cm}$, passando para $222 \mathrm{a}$ $230 \mathrm{~g} \mathrm{~kg}^{-1}$ em profundidade (Tabela 1), sem diferença entre os tratamentos. O grau de floculação de argila foi baixo, entre 0,21 e $0,48 \mathrm{~g} \mathrm{~kg}^{-1}$, independentemente das camadas e sistemas de preparo avaliados (Tabela 1). A densidade do solo variou de 1,35 a 1,67 Mg m ${ }^{3}$, sem diferença entre os sistemas (Tabela 1), e aumentando em profundidade, passando de $1,41 \mathrm{Mg} \mathrm{m}^{-3}$ na camada de $0-2,5 \mathrm{~cm}$, para $1,63 \mathrm{Mg} \mathrm{m}^{-3}$ em subsuperfície. Esses valores estariam abaixo do limite crítico de 1,70 a $1,75 \mathrm{Mg} \mathrm{m}^{-3}$, que seria restritivo ao desenvolvimento radicular em solo dessa classe textural, conforme proposição de ARSHAD et al. (1996). O aumento da densidade do solo acompanhou a diminuição do teor de matéria orgânica, com correlação significativa ( $r=-0,67$, Tabela 2$)$.

Ciência Rural, v.35, n.3, mai-jun, 2005. 
Tabela 1 - Carbono orgânico e atributos físicos e hídricos do solo

\begin{tabular}{|c|c|c|c|c|c|c|}
\hline \multirow{2}{*}{ Tratamento } & $\mathrm{CO}$ & Argila & GF & DS & $\mathrm{RP}$ & CHS \\
\hline & \multicolumn{3}{|c|}{$\mathrm{g} \mathrm{kg}^{-1}$} & $\mathrm{Mg} \mathrm{m}^{-3}$ & $\mathrm{MPa}$ & $\mathrm{cm} \mathrm{h}^{-1}$ \\
\hline \multicolumn{7}{|c|}{$0-2,5 \mathrm{~cm}$} \\
\hline PC & 13,1 b A & $190 \mathrm{~A}$ & 0,45 & $1,44 \mathrm{~B}$ & 0,48 а $A$ & 86,6 a $A$ \\
\hline PR & 13,7 b A & 205 A & 0,31 & $1,46 \mathrm{~B}$ & $0,28 \mathrm{bA}$ & $10,9 \mathrm{~d} C$ \\
\hline SD & 19,5 a $\mathrm{A}$ & 194 B & 0,37 & $1,35 \mathrm{~B}$ & 0,33 b $\mathrm{B}$ & 33,0 с A \\
\hline $\mathrm{CN}$ & 18,9 a $A$ & $188 \mathrm{~B}$ & 0,36 & 1,39 B & $0,41 \mathrm{ab} B$ & 51,2 b A \\
\hline Média & $16,3 \mathrm{~A}$ & $194 \mathrm{~B}$ & $0,38 \mathrm{~ns}$ & $1,41 \mathrm{C}$ & $0,38 \quad \mathrm{~B}$ & $45,4 \mathrm{~A}$ \\
\hline \multicolumn{7}{|c|}{$2,5-7,5 \mathrm{~cm}$} \\
\hline PC & 10,1 b B & 216 a bA & $0,32 \mathrm{~ns}$ & 1,57 a b A & $0,41 \quad \mathrm{cA}$ & 29,7 a B \\
\hline PR & 12,7 b A & 233 а A & 0,29 А В & 1,55 a b A & $0,37 \quad$ cA & 32,5 a B \\
\hline SD & 11,1 b B & 189 b B & $0,215 \mathrm{~B}$ & 1,59 а $\mathrm{A}$ & 0,75 a $A$ & 0,80 b B \\
\hline $\mathrm{CN}$ & 16,1 а $\mathrm{A}$ & 251 a A & 0,48 A & 1,46 b B & $0,69 \mathrm{~b} A$ & 2,90 b B \\
\hline Média & $12,5 \mathrm{~B}$ & $222 \mathrm{~A}$ & 0,32 & $1,54 \mathrm{~B}$ & 0,53 A & 16,5 B C \\
\hline \multicolumn{7}{|c|}{$7,5-12,5 \mathrm{~cm}$} \\
\hline PC & 10,3 A B & $217 \mathrm{~A}$ & $0,21 \mathrm{~ns}$ & $1,57 \mathrm{~A}$ & 0,42 cA & 16,1 a B \\
\hline PR & $11,0 \mathrm{~A}$ & 209 A & $0,29 \mathrm{~b}$ & $1,64 \mathrm{~A}$ & 0,35 cA & 2,70 a C \\
\hline SD & $10,4 \mathrm{~B}$ & $242 \mathrm{~A}$ & 0,32 a $A$ & $1,67 \mathrm{~A}$ & 0,75 a $A$ & $0,20 \mathrm{aB}$ \\
\hline $\mathrm{CN}$ & $11,5 \mathrm{~B}$ & $227 \mathrm{~A}$ & 0,34 a $\mathrm{A}$ & $1,64 \mathrm{~A}$ & $0,58 \mathrm{~b} \mathrm{~A}$ & $1,50 \mathrm{aB}$ \\
\hline Média & $10,8 \mathrm{C}$ & $224 \mathrm{~A}$ & 0,30 & $1,63 \mathrm{~A}$ & $0,52 \mathrm{~A}$ & $5,1 \mathrm{C}$ \\
\hline \multicolumn{7}{|c|}{$12,5-17,5 \mathrm{~cm}$} \\
\hline PC & 9,80 a b B & $216 \mathrm{~b} \mathrm{~A}$ & 0,37 a b ns & $1,60 \mathrm{~A}$ & 0,22 c $B$ & 27,3 b B \\
\hline PR & 8,90 b B & $216 \mathrm{~b} \mathrm{~A}$ & $0,26 \mathrm{~b}$ & $1,60 \mathrm{~A}$ & 0,33 bcA & 59,5 a A \\
\hline SD & 8,70 b B & 268 a A & $0,30 \mathrm{~b}$ & $1,65 \mathrm{~A}$ & 0,61 a $A$ & 2,8 с B \\
\hline $\mathrm{CN}$ & 11,9 а $B$ & $220 \mathrm{bAB}$ & 0,36 а & $1,63 \mathrm{~A}$ & $0,37 \mathrm{~b} \quad \mathrm{~B}$ & 4,3 с В \\
\hline Média & $9,8 \mathrm{C}$ & $230 \mathrm{~A}$ & 0,31 & $1,62 \mathrm{~A}$ & 0,38 B & 23,5 A B \\
\hline \multicolumn{7}{|c|}{$(0-17,5 \mathrm{~cm})$} \\
\hline PC & $10,5 \mathrm{~b}$ & $213 \mathrm{~ns}$ & $0,35 \mathrm{~ns}$ & $1,56 \mathrm{~ns}$ & $0,37 \mathrm{~b}$ & 33,3 a \\
\hline PR & 11,3 a b & 217 & 0,29 & 1,58 & $0,34 \mathrm{~b}$ & 28,6 a \\
\hline SD & 11,4 a b & 217 & 0,30 & 1,60 & 0,64 a & $5,80 \mathrm{~b}$ \\
\hline $\mathrm{CN}$ & 14,0 a & 226 & 0,38 & 1,55 & 0,50 a b & $9,80 \mathrm{~b}$ \\
\hline
\end{tabular}

CO = carbono orgânico; GF = grau de floculação de argila; DS = densidade do solo; RP = resistência ao penetrômetro; CHS = condutividade hidráulica saturada. Médias com letras diferentes, minúsculas para sistemas de preparo em mesma profundidade e maiúsculas para profundidades em cada sistema de preparo, diferem entre si pelo teste de Duncan em nível de $5 \%$ de probabilidade de erro e ns $=$ não significativo.

Maiores valores de densidade do solo na superfície sob SD, em relação ao PC têm sido relatados em muitos casos, e relacionados ao adensamento natural devido à ausência de revolvimento, como também, pela compactação ocasionada pelo tráfego de máquinas (DE MARIA et al., 1999). Esse comportamento não foi, entretanto, observado no solo em questão ainda que o experimento tenha sido conduzido em condições de preparo e semeadura mecanizados, como ocorre comumente nas lavouras comerciais. Diversos fatores podem ter contribuído para esses resultados, destacando-se que as operações de preparo de solo e trânsito de máquinas foram realizadas quando o solo encontrava-se no estado friável, ou seja, numa condição de umidade adequada, e que as coletas foram efetuadas nas entrelinhas de plantio. Em adição, a textura do solo, com 54\% de areia, determina a baixa coesão entre as partículas e o aumento no teor de CO na camada superficial do solo em SD aumentou a estabilidade de agregados e, conseqüentemente, a resistência do solo a pressões exercidas pelas máquinas e seus implementos. Contudo, vale salientar que o referido sistema, embora preconize a não revolvimento do solo, pode promover alguma movimentação desse, pelos mecanismos sulcadores das semeadoras.

A resistência do solo ao penetrômetro (RP) variou de 0,22 a 0,75 MPa nos diferentes sistemas e profundidades analisadas (Tabela 1). Embora o equipamento utilizado provoque cisalhamento do solo e subestime a resistência do solo, os valores podem ser 
Tabela 2 - Coeficientes de correlação de Pearson entre os atributos do solo analisado.

\begin{tabular}{|c|c|c|c|c|c|c|c|c|c|c|}
\hline & $\mathrm{CO}$ & Argila & GF & DS & Ма & Mi & PT & $\mathrm{RP}$ & CHS & $\mathrm{AD}$ \\
\hline$\overline{\mathrm{CO}}$ & & $-0,05$ (ns) & $0,33(*)$ & $-0,67(*)$ & 0,15 (ns) & $0,65\left(^{*}\right)$ & $0,49\left(^{*}\right)$ & 0,04 (ns) & 0,13 (ns) & $-0,36(*)$ \\
\hline Argila & & & $0,56(*)$ & 0,13 (ns) & $-0,20$ (ns) & $-0,01(\mathrm{~ns})$ & $-0,17$ (ns) & 0,21 (ns) & $-0,16$ (ns) & 0,02 (ns) \\
\hline GF & & & & $-0,32\left(^{*}\right)$ & 0,14 (ns) & $0,33\left(^{*}\right)$ & 0,29 (ns) & $-0,07$ (ns) & $-0,01(\mathrm{~ns})$ & $-0,01$ (ns) \\
\hline DS & & & & & $-0,66(*)$ & $-0,58 \quad(*)$ & $-0,87 \quad(*)$ & 0,22 (ns) & $-0,42(*)$ & 0,21 (ns) \\
\hline Ма & & & & & & 0,01 (ns) & $0,84(*)$ & $-0,11(\mathrm{~ns})$ & $0,38(*)$ & 0,18 (ns) \\
\hline Mi & & & & & & & $0,54\left(^{*}\right)$ & $-0,12$ (ns) & 0,08 (ns) & $-0,31\left(^{*}\right)$ \\
\hline PT & & & & & & & & $-0,15$ (ns) & $\left.0,37{ }^{*}\right)$ & $-0,02(\mathrm{~ns})$ \\
\hline $\mathrm{RP}$ & & & & & & & & & $-0,42(*)$ & 0,13 (ns) \\
\hline CHS & & & & & & & & & & $-0,02(\mathrm{~ns})$ \\
\hline
\end{tabular}

$\mathrm{CO}$ = carbono orgânico; $\mathrm{GF}$ = grau de floculação de argila; $\mathrm{DS}$ = densidade do solo; $\mathrm{Ma}=$ macroporosidade; $\mathrm{Mi}=$ microporosidade; $\mathrm{PT}=$ porosidade total; $\mathrm{RP}$ = resistência ao penetrômetro; $\mathrm{CHS}$ = condutividade hidráulica saturada; $\mathrm{AD}$ = água disponível.

$*$ = Significativo a $5 \%$ de probabilidade de erro.

ns = Não significativo.

considerados baixos, possivelmente em decorrência da elevada umidade do solo, a qual variou de 0,27 a $0,35 \mathrm{~m}^{3} \mathrm{~m}^{-3}$ no momento da determinação. Usualmente maiores valores de resistência ao penetrômetro têm sido verificados em solos sob SD em relação ao PC (TORMENA et al., 1999), o que tem sido relacionado ao seu estado de compactação e umidade do solo. Todavia, a correlação da RP com a densidade do solo não foi significativa $(r=0,23$, Tabela 2$)$ para o solo estudado.

Entre os sistemas de preparo, houve pequenas variações da resistência ao penetrômetro em profundidade. A menor resistência em SD na

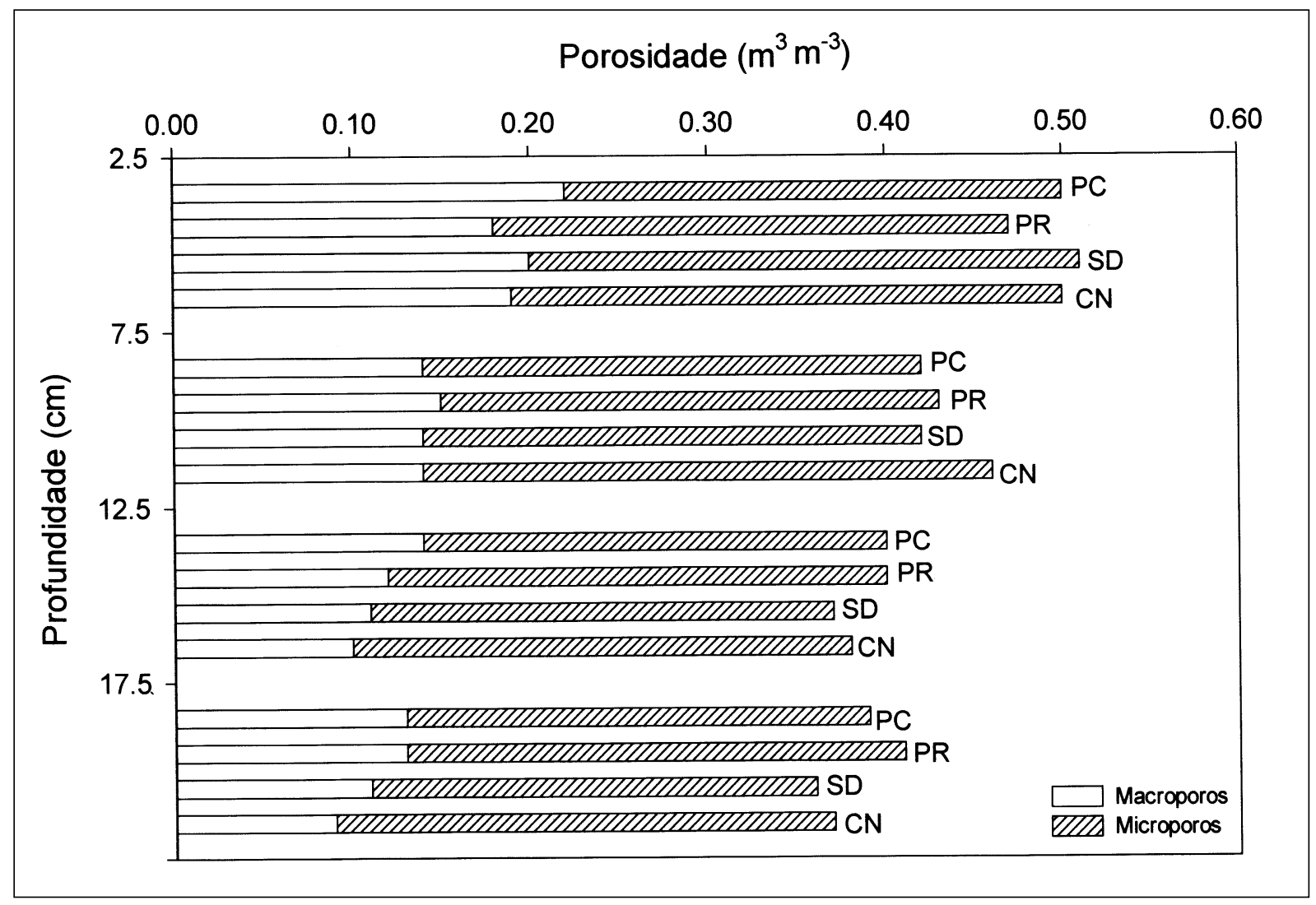

Figura 1 - Distribuição da porosidade do solo sob diferentes sistemas de manejo (PC: preparo convencional; PR: preparo reduzido; SD: semeadura direta e $\mathrm{CN}$ : campo nativo)

Ciência Rural, v.35, n.3, mai-jun, 2005. 
camada de 0-2,5 cm, possivelmente está relacionada a aspectos ligados à estrutura e agregação, uma vez que a constituição do solo em termos de argila e carbono orgânico não teve relação com esse atributo (Tabela 2). Na camada de $12,5-17,5$ cm, o PC e PR apresentaram menor resistência ao penetrômetro em relação à SD. Esse comportamento pode ser devido ao revolvimento periódico do solo efetuado em PC e PR. Apesar dos maiores valores de resistência ao penetrômetro no solo em SD, esses foram baixos e não restritivos ao desenvolvimento de raízes, resultado reforçado pelos valores de macroporosidade (Tabela 1 ).

A condutividade hidráulica saturada (CHS) teve ampla variação entre os sistemas e profundidades avaliadas, desde valores próximos a zero até $86,6 \mathrm{~cm} \mathrm{~h}^{-1}$ (Tabela 1). Um fato que deve ter contribuído para essa elevada amplitude de valores foi o pequeno volume das amostras, aliado à presença de bioporos contínuos esparsos, os quais demonstram grande capacidade de transmissão de água (LOGSDON et al., 1990).

Na camada superficial, a CHS foi superior no PC em relação aos demais sistemas de preparo de solo . Isso possivelmente pode ser explicado pelo efeito da mobilização do solo, com tendência ao aumento dos macroporos. Na camada de 2,5-12,5, pode-se notar que, mesmo na condição natural de $\mathrm{CN}$, esse solo apresenta redução na condutividade hidráulica saturada.

Em termos de distribuição dos poros do solo (Figura 1), a macroporosidade no perfil variou de 0,09 a $0,20 \mathrm{~m}^{3} \mathrm{~m}^{-3}$, e não foi influenciada pelos sistemas de preparo do solo. Esses valores de macroporosidade são considerados adequados para as plantas, em termos de garantia de aeração do sistema radicular (REYNOLDS et al., 2002), cujo limite crítico é de $10 \%$ do volume total de poros. Deve-se ressaltar que o fluxo de gases bem como o movimento de água no solo, estão intimamente relacionados ao seu volume de macroporos, ou seja, a garantia da oxigenação radicular bem como a capacidade de infiltração e redistribuição de água no perfil dependem dessa propriedade. Sua efetividade, nesses casos, depende além da quantidade, da sua continuidade em profundidade e da abertura à superfície. Normalmente o revolvimento do solo promove um aumento temporário da macroporosidade, quando comparado à garantia de aeração do sistema radicular (REYNOLDS et al., 2002), cujo limite crítico é de $10 \%$ do volume total de poros. Deve-se ressaltar que o fluxo de gases bem como o movimento de água no solo, estão intimamente relacionados ao seu volume de macroporos, ou seja, a garantia da oxigenação radicular bem como a capacidade de infiltração e redistribuição de água no perfil dependem dessa propriedade. Sua efetividade, nesses casos, de- pende além da quantidade, da sua continuidade em profundidade e da abertura à superfície. Normalmente o revolvimento do solo promove um aumento temporário da macroporosidade, quando comparado à SD. Esse efeito, entretanto, é eliminado pela reconsolidação ou adensamento natural do solo o qual, no momento da coleta poderia ser considerado como o valor anual máximo considerando-se que o último revolvimento do solo foi realizado aproximadamente 12 meses anterior à amostragem do solo.

A microporosidade variou de 0,25 a $0,32 \mathrm{~m}^{3} \mathrm{~m}^{-3}$ nas amostras analisadas, tendo menor amplitude do que a macroporosidade. A porosidade total variou de 0,36 a $0,52 \mathrm{~m}^{3} \mathrm{~m}^{-3}$ evidenciando maior influência da profundidade e pouca interferência do sistema de preparo adotado. A porosidade total foi maior em superfície, quando comparada à subsuperfície (Tabela 1). Esse comportamento pode ser atribuído aos ciclos sucessivos de umedecimento-secamento que ocorrem na superfície do solo, além da melhoria de sua estrutura pela intensa atividade biológica e acúmulo de matéria orgânica.

Armazenamento de água disponível às plantas

As curvas de retenção de água sob diferentes tensões foram semelhantes em todas as profundidades, e não foram influenciadas pelos sistemas de preparo do solo (Figura 2). $\mathrm{O}$ armazenamento de água variou de 0,27 a $0,37 \mathrm{~m}^{3} \mathrm{~m}^{-3}$ na condição de solo saturado $(0 \mathrm{kPa})$. A quantidade de água presente no potencial de $-10 \mathrm{kPa}$, referida na literatura como capacidade de campo para solos com textura franco-arenosa (CARLESSO, 1995) variou de 0,25 a $0,31 \mathrm{~m}^{3} \mathrm{~m}^{-3}$ na camada superficial (0-2,5 $\mathrm{cm})$, e de 0,25 a $0,27 \mathrm{~m}^{3} \mathrm{~m}^{-3}$ em subsuperfície. No potencial de $-1.500 \mathrm{kPa}$, os teores de água variaram de 0,17 a 0,25 $\mathrm{m}^{3} \mathrm{~m}^{-3}$ na camada estudada. Tanto o volume de água a $10 \mathrm{kPa}$ como a $-1.500 \mathrm{kPa}$ não foram afetados pelos sistemas de manejo.

As variações observadas entre as curvas podem ser relacionadas à influência da estrutura e composição dos materiais em termos de matéria orgânica e argila, o que determina alterações na quantidade e distribuição de poros. Nesse caso, a compactação provocada pelo uso agrícola normalmente ocasiona uma drástica redução na macroporosidade (SILVA et al., 1986) podendo haver, em muitos casos, maior volume de microporos, o que aumentaria a capacidade de armazenamento de água (BERTOL \& SANTOS, 1995).

A água disponível, considerada como o volume entre capacidade de campo $(-10 \mathrm{kPa})$ e o ponto de murcha permanente $(-1.500 \mathrm{kPa})$ variou de 0,05 a $0,09 \mathrm{~m}^{3} \mathrm{~m}^{-3}$ (Figura 3) e não foi afetada pelos sistemas de preparo de solo. Esses valores estão abaixo da capacidade ideal de armazenamento de 


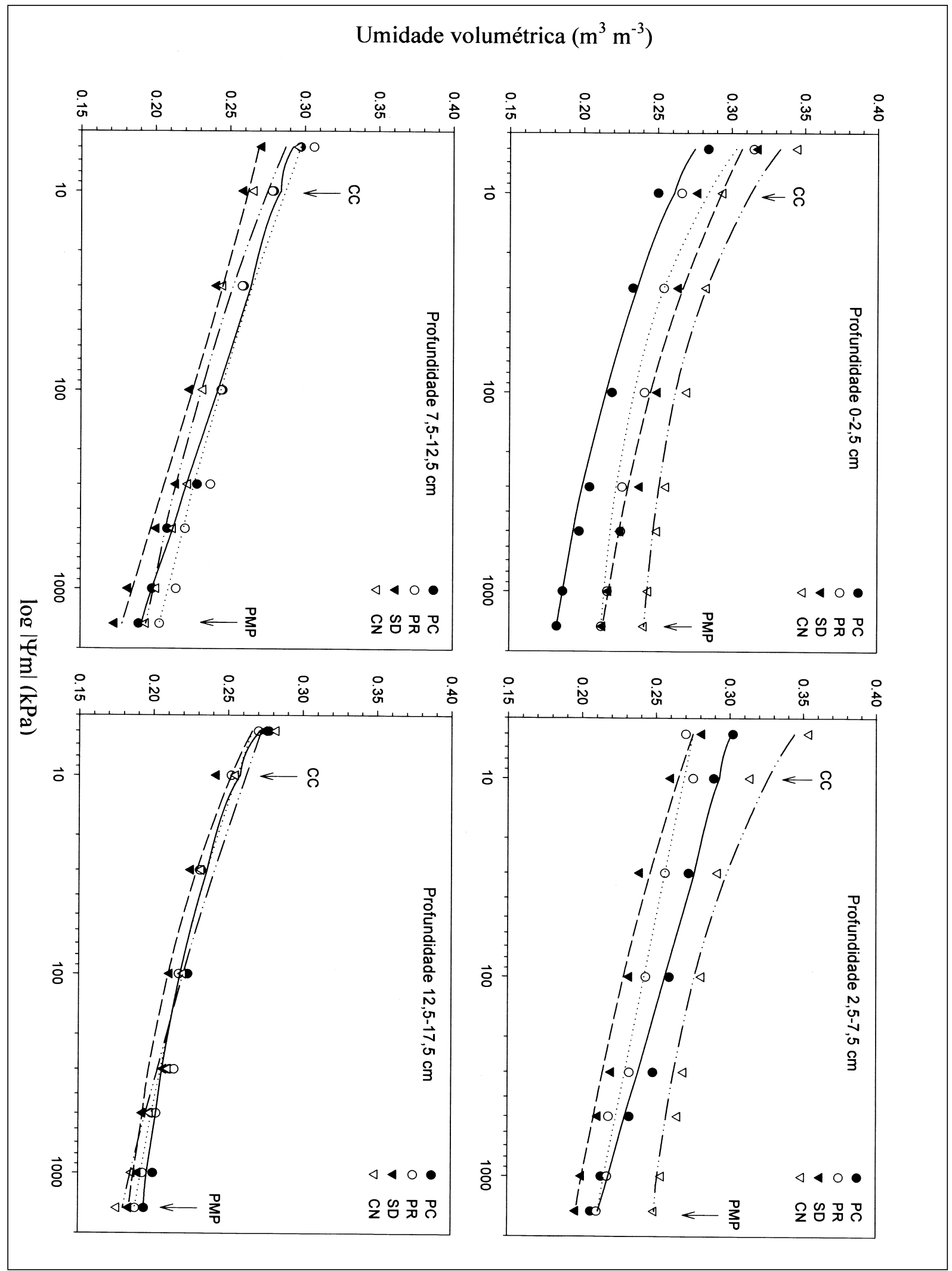

Figura 2 - Curvas de retenção de água no solo, sob diferentes sistemas de manejo (PC: preparo convencional; PR: preparo reduzido; SD: semeadura direta e CN: campo nativo. CC: capacidade de campo; PMP: ponto de murcha permanente).

Ciência Rural, v.35, n.3, mai-jun, 2005. 


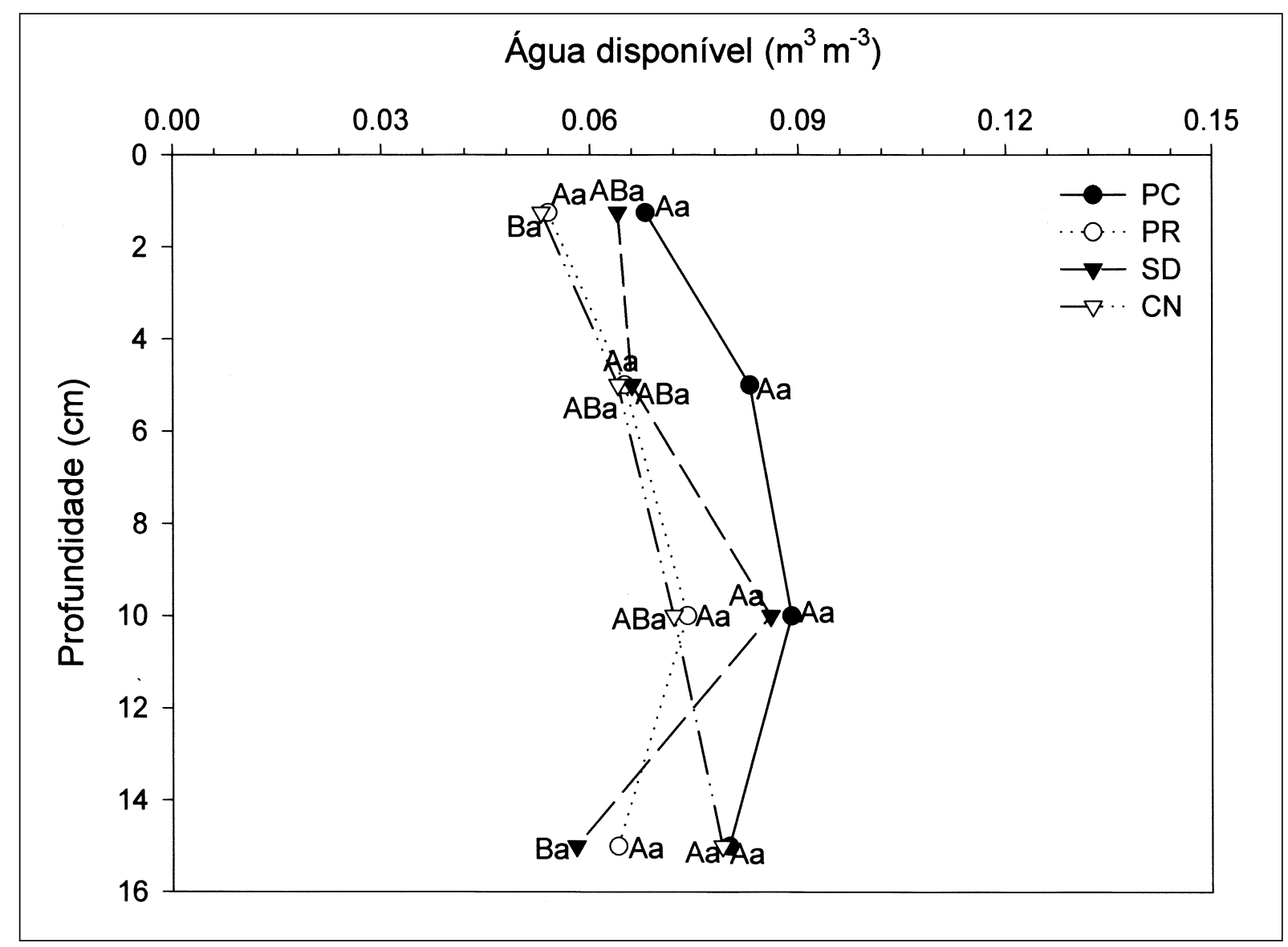

Figura 3 - Água disponível do solo sob diferentes sistemas de manejo (PC: preparo convencional; PR: preparo reduzido; SD: semeadura direta e CN: campo nativo). Letras maiúsculas comparam o efeito da profundidade em cada manejo e, minúsculas, os manejos em cada profundidade.

água no solo que, conforme sugerido por REYNOLDS et al. (2002), situa-se entre 0,15 e $0,20 \mathrm{~m}^{3} \mathrm{~m}^{-3}$. Essa é uma propriedade do solo de vital importância na economia de água das plantas (REICHARDT, 1996). Em um Argissolo Amarelo, ROJAS \& VAN LIER (1999) observaram maior retenção de água na camada de $0-20 \mathrm{~cm}$ de profundidade do solo em PC em relação à SD, o que foi relacionado ao aumento da microporosidade do solo. Todavia, no Argissolo Vermelho avaliado no presente estudo, o aumento da microporosidade não foi verificado no solo em PC, e possivelmente, uma maior disponibilidade hídrica no solo em SD, principalmente na fase inicial do estabelecimento das culturas, seja decorrente da redução da evaporação da água do solo advinda da manutenção e cobertura do solo pelos resíduos culturais (SALTON \& MIELNICZUK, 1995). Nesse sentido, é provável que o solo em PR apresente um comportamento intermediário ao PC e SD.

\section{CONCLUSÕES}

A adoção de SD aumentou os teores de carbono orgânico na camada superficial do solo e a resistência ao penetrômetro em subsuperfície, em relação ao PC. O revolvimento do solo não influenciou a porosidade total e a distribuição do tamanho de poros, mas aumentou a condutividade hidráulica saturada em superfície.

O solo estudado não apresentou restrições ao desenvolvimento radicular em termos de densidade do solo, macroporosidade e resistência ao penetrômetro sob nenhum sistema de preparo.

Do ponto de vista hídrico, as curvas de retenção de água e a água disponível não foram afetadas pelos sistemas de preparo avaliados.

\section{REFERÊNCIASBIBLIOGRÁFICAS}

ALEGRE, J.C. et al. Tillage systems and soil properties in Latin America. Soil Tillage Research, v.20, p.147-163, 1991. 
ARSHAD, M.A. et al. Physical tests for monitoring soil quality. In: DORAN, J.W.; JONES, A.J. (Eds.). Methods for assessing soil quality. Madison : Soil Science Society of América, 1996. p.123-141.

BAYER, C. et al. Efeitos de sistemas de preparo e de cultura na dinâmica da matéria orgânica e na mitigação das emissões de $\mathrm{CO}_{2}$. Revista Brasileira de Ciência do Solo, v.24, p.599607, 2000.

BERTOL, I.; SANTOS, J.C.P. Uso do solo e propriedades físico-hídricas no Planalto Catarinense. Pesquisa Agropecuária Brasileira, v.30, p.263-267, 1995.

CARLESSO, R. Absorção de água pelas plantas: água disponível versus água extraível e a produtividade das culturas. Ciência Rural, Santa Maria, v.25, n.1, p.83-188, 1995.

CASTRO FILHO, C. et al. Aggregate stability under different soil management systems in a Red Latosol in State of Parana, Brazil. Soil Tillage Research, v.65, p.45-51, 2002.

COSTA, F.S. et al. Propriedades físicas de um Latossolo Bruno afetadas pelos sistemas de semeadura direta e preparo convencional. Revista Brasileira de Ciência do Solo, v.27, p.527-535, 2003.

DE MARIA, I.C. et al. Atributos físicos do solo e crescimento radicular da soja em Latossolo Roxo sob diferentes métodos de preparo do solo. Revista Brasileira de Ciência do Solo, v.23, p.703-709, 1999.

DOURADO-NETO, D. et al. Software to model soil water retention curves (SWRC, version 2.00). Scientia Agricola, v.57, p.191-192, 2000.

EMPRESA BRASILEIRA DE PESQUISA AGROPECUÁRIA, Centro Nacional de Pesquisa de Solos. Manual de métodos de análise de solo. 2.ed. Rio de Janeiro : Embrapa, 1997. 212p.

LOGSDON, S.D. et al. Macroporosity and its relation to saturated hydraulic conductivity under different tillage practices.
Soil Science Society of American Journal, n.54, p.10961101, 1990.

REICHARDT, K. Dinâmica da matéria e da energia em ecossistemas. 2.ed. Piracicaba : USP/ESALQ, Depto. de Física e Meteorologia, 1996. 513p.

REYNOLDS, W.D. et al. Indicators of good soil physical quality: density and storage parameters. Geoderma, v.110, p.131146, 2002

ROJAS, C.A.L.; VAN LIER, Q.J. Alterações físicas e hídricas de um Podzólico em função de sistemas de preparo. Pesquisa Agropecuária Gaúcha, v.5, n.1, p.105-115, 1999.

SALTON, J.C.; MIELNICZUK, J. Relações entre sistemas de preparo, temperatura e umidade de um Podzólico Vermelho Escuro de Eldorado do Sul (RS). Revista Brasileira de Ciência do Solo, v.19, p.313-319, 1995.

SILVA, A.P. et al. Influência da compactação nas propriedades físicas de dois Latossolos. Revista Brasileira de Ciência do Solo, v.10, p.91-95, 1986.

TEDESCO, M.J. et al. Análises de solo, plantas e outros materiais. 2.ed. Porto Alegre : Universidade Federal do Rio Grande do Sul, 1995. 174p. (Boletim Técnico de Solos, 5).

TORMENA, C.A. et al. Soil physical quality of a Brazilian Oxisol under two tillage systems using the least limiting water range approach. Soil Tillage Research, v.52, p.223-232, 1999.

UNGER, P.W.; CASSEL, D.K. Tillage implement disturbance effects on soil properties related to soil and water conservation: a literature review. Soil Tillage Research, v.19, p.363-382, 1991.

VAN GENUCHTEN, M.T. A closed form equation for predicting hydraulic conductivity of unsaturated soils. Soil Science Society of American Journal, n.44, p.892-898, 1980. 